\title{
Seismic infrared anomalies detection in the case of the Wenchuan earthquake using bi-angular advanced along-track scanning radiometer data
}

\author{
Pan Xiong ${ }^{1,{ }^{\star}}$, Xuhui Shen ${ }^{1}$, Xingfa $\mathrm{Gu}^{2}$, Qingyan Meng ${ }^{2}$, Liming Zhao ${ }^{2}$, Yanhua Zhao ${ }^{3}$, \\ Yan $\mathrm{Li}^{3}$, Jianting Dong ${ }^{3}$ \\ ${ }^{1}$ Institute of Earthquake Science, China Earthquake Administration, Beijing, China \\ ${ }^{2}$ Intitute of Remote Sensing Applications and Digital Earth, Chinese Academy of Sciences, Beijing, China \\ ${ }^{3}$ Beijing Institute of Space Mechanics and Electricity, Beijing, China
}

\section{Article history}

Received December 1, 2014; accepted March 5, 2015.

Subject classification:

Seismic monitoring, Infrared bi-angular, Robustness of satellite techniques, Earthquake infrared radiation anomalies.

\begin{abstract}
The paper has developed Robust Satellite data analysis Technique (RST) to detect seismic anomalies in the case of the Wenchuan earthquake occurred on May 12, 2008, using the bi-angular Advanced Along-Track Scanning Radiometer (AATSR) gridded brightness temperature (BT) data based on spatial/temporal continuity and confutation analysis. The proposed method has been applied to analyze the Wenchuan earthquake with longitude from $95^{\circ} \mathrm{E}$ to $111^{\circ} \mathrm{E}$ and latitude from $23^{\circ} \mathrm{N}$ to $39^{\circ} \mathrm{N}$, and a full data-set of 7 years data from 2003 to 2009 during the months of April and May has been analyzed. Combining with the rupture structure data of the Wenchuan earthquake, the analyzed results indicate that: the main structure activity (the Yingxiu-Beichuan fault) characteristics of the Wenchuan earthquake can be identified and extracted using the bi-angular AATSR nadir and forward brightness temperature data, and the seismic infrared radiation anomalies detected by the AATSR nadir brightness temperature is more close to the Yingxiu-Beichuan fault.
\end{abstract}

\section{Introduction}

In the past 20 years, with the development of satellite remote sensing, the infrared remote sensing data has become increasingly abundant, which provides guarantee for the study of earthquake infrared remote sensing, and the study of earthquake infrared remote sensing has also made great progress. These studies analytically compare images of pre (vs. post) earthquake satellite TIR imagery [Tronin et al. 2002]; study outgoing longwave radiation (OLR) data and identify anomalous variations prior to a number of medium to large earthquakes [Defu et al. 1997, Ouzounov et al. 2007, Xiong et al. 2010]; perform a multispectral thermal infrared component analysis during earthquakes by using Land Surface Temperature [Ouzounov and Freund
2004, Tronin et al. 2004]; or assess the anomalous surface latent heat flux peaks a few days prior to the earthquake event [Cervone et al. 2004, 2005].

At the same time, the technology of multi-angle infrared remote sensing has made great advances, which has become a frontier research field, but the applied research of earthquake science using multi-angle infrared remote sensing data is still blank. Therefore, the development of seismic infrared anomalies identification and extraction using multi-angle remote sensing data will be a new technology and method for studying earthquake infrared anomalies.

Actually, the main problem associated with seismic anomalies detection is lack of rigorous definition for TIR anomalies in the current study. A possible solution to these problems is to employ a new approach and an advanced data analysis technique to detect earthquake anomalies embedded in TIR remote sensing satellite data. Recently, a data analysis technique named the Robust Satellite Data Analysis Technique (RST) [Tramutoli 2007] has been proposed for natural and environmental hazards monitoring and mitigation. This technique has already been validated in the case of many earthquakes [Tramutoli et al. 2001, Filizzola et al. 2004, Corrado et al. 2005, Tramutoli 2005, Aliano et al. 2007, Xiong et al. 2013].

Based on the characteristics of the Envisat bi-angular AATSR data, this paper has introduced and developed the method of the RST to detect seismic anomalies, and formed a set of data processing procedure. On this basis, this paper has carried out the case study of the Wenchuan earthquake occurred on May 12, 2008, com- 


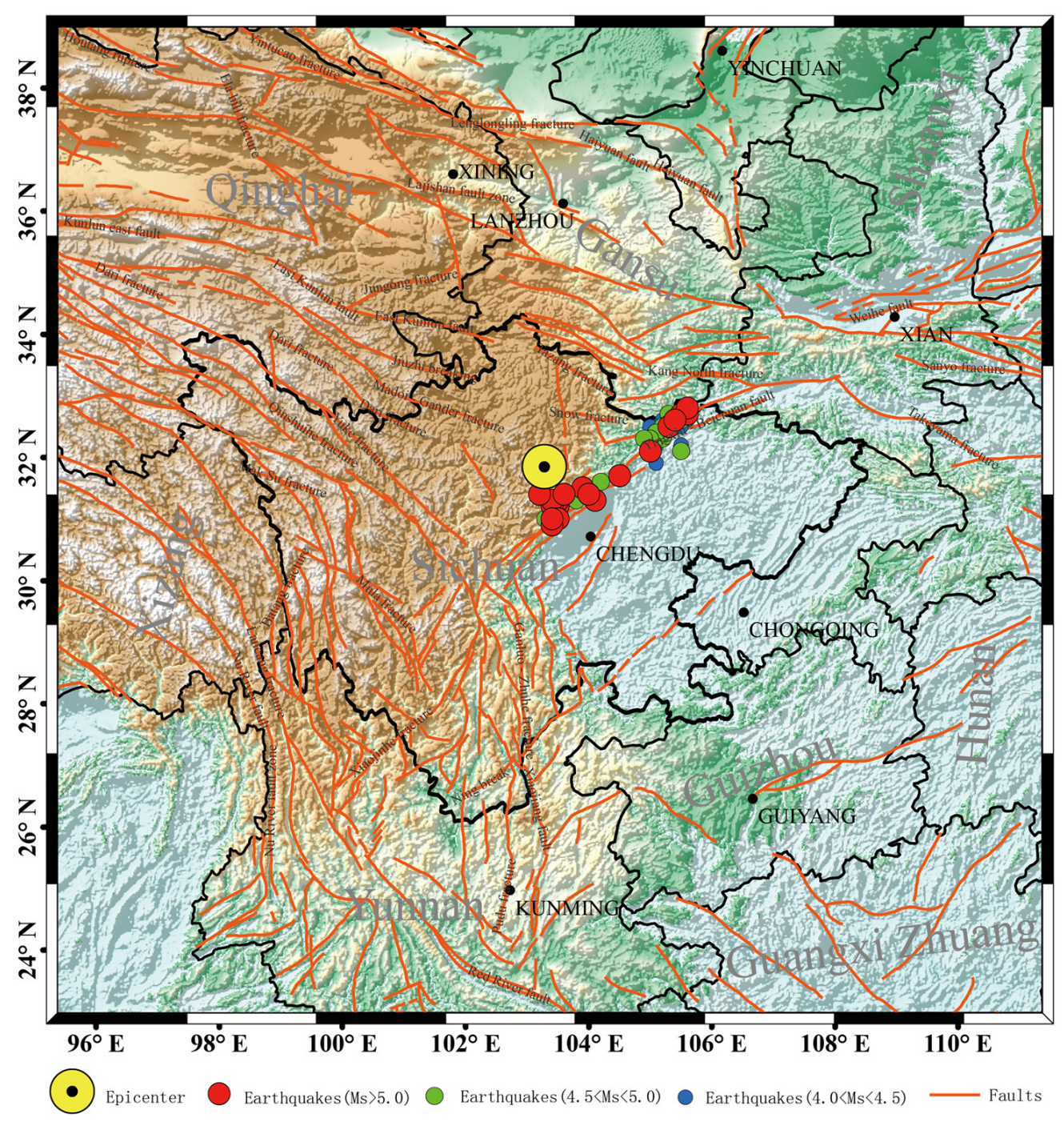

Figure 1. The investigated area of the Wenchuan earthquake. The epicenter of the Wenchuan earthquake occurred on May 12, 2008, is marked with a yellow cride, the main faults is marked with pink line.

bined with the tectonic explanation of the spatial and temporal continuity of the abnormal phenomena, the analyzed results have indicated that there are a number of anomalies associated with the possible seismic characteristics during the Wenchuan earthquake.

\section{Earthquake and data}

In this study, the Wenchuan earthquake is selected for evaluating the proposed method. The Wenchuan earthquake of magnitude 8.0 is the largest earthquake in China in the past thirty years. It occurred on May 12, 2008 , the location of the epicenter is at $30.986^{\circ} \mathrm{N}$, $103.364^{\circ} \mathrm{E}$, and the depth is $19 \mathrm{~km}$. The main earthquake was followed by a series of smaller aftershocks (Figure 1).

The Advanced Along-Track Scanning Radiometer (AATSR) onboard ESA's Envisat spacecraft has three visible/ near-infrared channels at $0.55,0.67$ and $0.87 \mathrm{mi}-$ cron, designed specifically for remote-sensing applications over land and a visible channel at 1.6 micron which is used primarily for cloud clearing, three channels at the thermal infrared wavelengths of 3.7, 11 and $12 \mu \mathrm{m}$, from which surface temperatures are derived over both sea and land surfaces [Llewellyn-Jones et al. 2001]. The nominal spatial resolution of AATSR is $1 \mathrm{~km} \times 1 \mathrm{~km}$ in the nadir view and $1.5 \mathrm{~km} \times 2 \mathrm{~km}$ in the forward view, with a swath width of about $500 \mathrm{~km}$. Equator crossing time is 10:00 A.M. local time (descending node) and revisit time is about 3 days [Coll et al. 2012].

The AATSR has two on-board calibration mechanisms, low-noise detectors and mechanical coolers that provide high radiometric accuracy and stability to the TIR data (better than $0.05 \mathrm{~K}$ for the 11 and $12 \mu \mathrm{m}$ bands). A special feature of the AATSR is its conical scanning mechanism to give a dual view of the Earth's surface, first in the forward view at an angle of around $55^{\circ}$ and $150 \mathrm{~s}$ later in the nadir view at an angle close to vertical (from $0^{\circ}$ to $21.7^{\circ}$ ). From two views with different atmospheric path lengths, it is possible to obtain independent information about the atmospheric contributions to 
the signal, and perform an accurate atmospheric correction and thus enable more precise data [ESA 2007].

The AATSR data used in this paper is usually provided so called Gridded Brightness Temperature/Reflectance (GBTR) product, which is the single Level 1B product from AATSR. It contains cloud-free top-ofatmosphere (TOA) brightness temperature (BT) values for the three infrared channels and reflectance values for the $1.6 \mu \mathrm{m}$ and visible channels, and all pixels are co-located and resampled to a $1 \mathrm{~km}$ latitude-longitude grid [ESA 2007]. In this paper we utilise the bi-angular $12 \mu \mathrm{m}$ brightness temperature data to detect seismic anomalies.

A data-set used here is the bi-angular AATSR gridded BT, a coverage of longitude from 95 east longitude to 111 east longitude and latitude from 23 north latitude to 39 north latitude, The duration is from 2003 to 2009 during the months of April and May has been selected and processed.

\section{Methodology}

There are several methods to choose for the analysis of TIR data, mainly including the Eddy field calculation mean [Defu et al.1997, Ouzounov et al. 2007], the wavelet time-frequency analysis [Cervone et al. 2005, Xiong et al. 2009a, Xiong et al. 2009b, Xiong et al. 2010, Xiong et al. 2011] and the Robust Satellite data analysis Technique [Tramutoli 1998]. The RST method is based on a preliminary multi-temporal analysis on several years of satellite TIR records, which is devoted to characterize the TIR signal for each pixel of the satellite image processed. This previous study concluded that, IR anomalies could be identified within TIR data related to an earthquake [Tramutoli et al. 2001, Tramutoli 2005, Tramutoli et al. 2005, Tramutoli 2007, Temimi et al. 2011, Tramutoli et al. 2013, Xiong et al. 2013]. Each step of the RST method for detecting seismic anomalies using bi-angular AATSR data will be explained and detailed in the following.

\subsection{Calculating the differential variable $\Delta$}

Calculating the differential variable $\Delta \mathrm{T}$ is expected to reduce possible contributions due to day-to-day and/or year-to-year climatological changes and/or season time-drifts, the differential variable $\Delta \mathrm{T}$ is the value of the difference between the punctual value of AATSR $\mathrm{BT}$ and its average computed on the investigated area by taking consideration of only cloud-free locations, all belonging to the same, land or sea.

The first step in calculating the differential variable $\Delta \mathrm{T}$ is to build a cloud mask: hereinafter, we use the nadirforward tests [Závody et al. 2000]. For each pixel the difference $\mathrm{T} 11-\mathrm{T} 12$ is determined, and used to predict the view difference using this relationship. The actual view difference is compared with the prediction, and if they differ by more than a pre-defined threshold, the pixel is assumed to be cloudy [ESA 2007], after performing the cloud detection one can build an image $\mathrm{CM}(\mathrm{x}, \mathrm{y})$ for each pixel $\mathrm{x}, \mathrm{y}$ of the scene $\mathrm{CM}=1$ or $\mathrm{CM}=0$ if the location has been recognized as clear or cloudy, respectively.

Given latitude and longitude of the image pixel, the surface type for each image pixel is derived from land/sea mask information obtained by an external AATSR auxiliary product, after performing the land/sea identification one can build an image LS ( $\mathrm{x}, \mathrm{y})$ having for each pixel $\mathrm{x}, \mathrm{y}$ of the scene with $\mathrm{LS}=1$ or $\mathrm{LS}=0$ if the location has been recognized as sea or land.

Computing the average $T(t)$ for the sea using only pixels over the scene which have $\mathrm{CM}=1$ and $\mathrm{LS}=1$ and for the land using only pixels over the scene which have $\mathrm{CM}=1$ and $\mathrm{LS}=0$.

The last step is to calculate differential variable by using Formula (1)

$$
\Delta T=T(r, t)-T(t)
$$

where, $r \equiv(x, y)$ represents location coordinates of the pixel centre on a satellite image; $t$ is the time of image acquisition.

\subsection{Calculating the reference field}

In order to calculate the reference field for this study, we use a binning algorithm to preprocess the selected data, in which binning refers to as the process of distributing the contributions of pixels to be processed in satellite coordinates to a fixed grid using a geographic reference system. In most cases a sinusoidal projection is used to generate a grid comprising a fixed number of equal area bins with global coverage [Campbell et al. 1995].

We use cloud free records from the selected data set $(\mathrm{t} \in \tau)$ to compute the reference field for mean $\mu_{\Delta T}(r)$ and standard deviation $\sigma_{\Delta T}(r)$ at the location $r \equiv(x, y)$ using the following equations:

$$
\begin{gathered}
\mu_{\Delta T}(r)=\frac{1}{N} \sum_{t \in \tau}^{N} \Delta T(r, t) \\
\sigma_{\Delta T}(r)=\sqrt{\frac{1}{N} \sum_{t \in \tau}^{N}\left(\Delta T(r, t)-\mu_{\Delta T}(r)\right)^{2}}
\end{gathered}
$$

The computed $\mu_{\Delta T}(r)$ and $\sigma_{\Delta T}(r)$ reference field shown in Figure 2.

\subsection{Anomalous detection step}

Anomalous TIR of bi-angular AATSR data are detected by an index as used in [Tramutoli 2007], RETIRA 

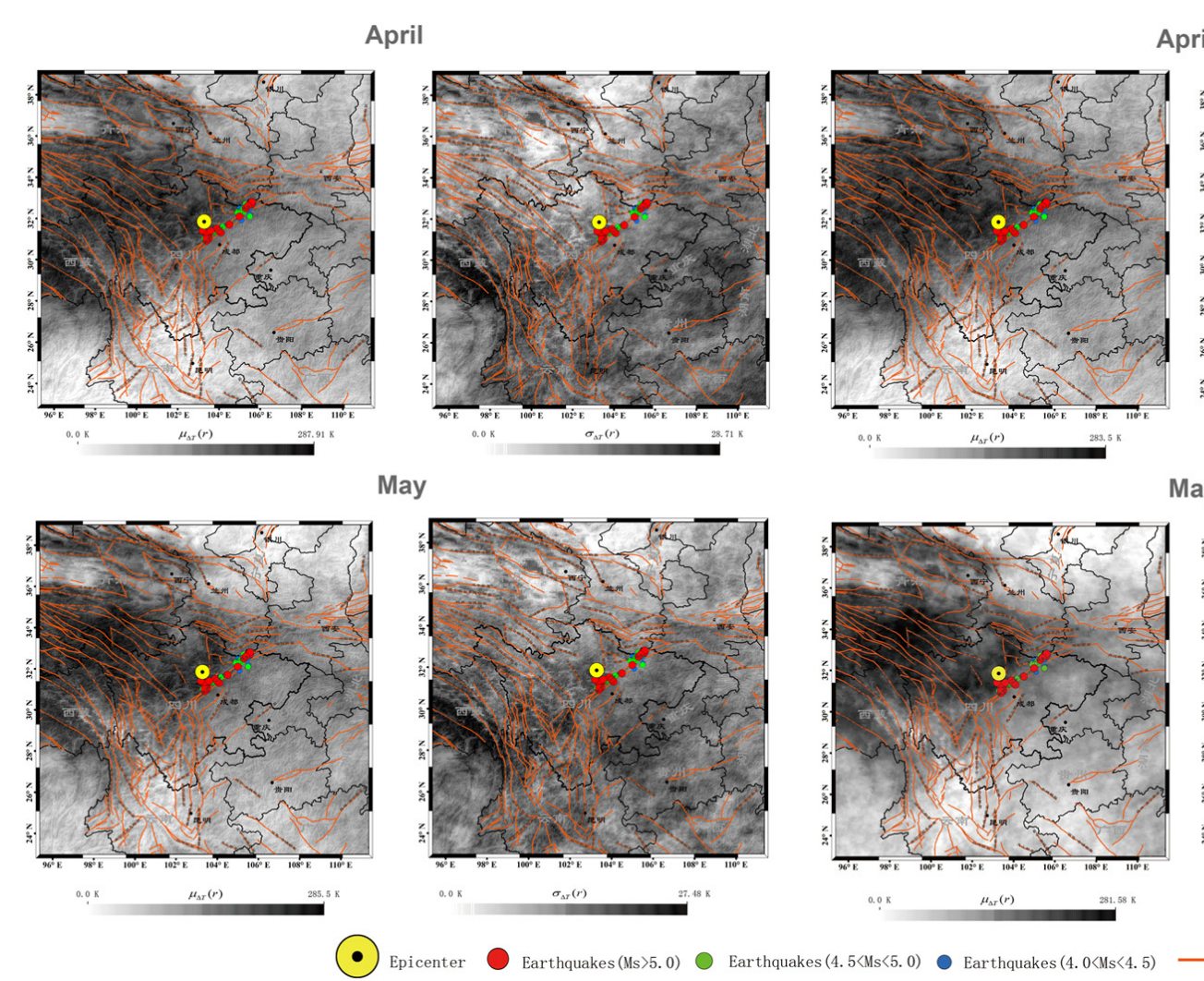

April

Figure 2. The reference field for the investigated area of forward view and nadir view computed from bi-angular AATSR data from 2003 to 2008 during the months of April (left panel) and May (right panel).

(Robust Estimator of TIR Anomalies), which can be defined as follows:

$$
\oplus_{\Delta T}(r)=\frac{\Delta T(r, t)-\mu_{\Delta T}(r)}{\sigma_{\Delta T}(r)}
$$

The difference $\Delta T(r, t)-\mu_{\Delta T}(r)$ then represents the Signal (S) to be investigated for its possible relation with seismic activities. It is always evaluated by comparison with the corresponding natural/observational Noise $(\mathrm{N})$, represented by $\sigma_{\Delta T}(r)$ which describes the overall (local) variability of $S$ including all (natural and observational, known and unknown) sources of its variability, as historically observed at the same site in similar observational conditions (sensor, time of day, month, etc.). This way, the relative importance of the measured TIR signal (or the intensity of anomalous TIR transients) can naturally be evaluated in terms of $\mathrm{S} / \mathrm{N}$ ratio by the RETIRA index. Moreover the larger is $\sigma_{\Delta T}(r)$, the lower will be $\oplus_{\Delta T}(r)$, so that the RETIRA index results intrinsically protects against false alarm proliferation [Tramutoli 2005].

\section{Results and discussion}

Using the above method and the bi-angular AATSR top-of-atmosphere BT data from April 6, 2008, to May 13, 2008, we get the curves of results of the RETIRA index computation on the investigated area before and after the Wenchuan earthquake using AATSR nadir view and forward view data. Pixels with $\oplus_{\Delta T}(r)>4.0$ are depicted in mars red, pixels with $3.5<\oplus_{\Delta T}(r)<4$ are depicted in seville orange, pixels with $3.0<\oplus_{\Delta T}(r)<3.5$ are depicted in solar yellow, pixels with $2.5<\oplus_{\Delta T}(r)<3.0$ are depicted in autunite yellow, pixels with $2.0<\oplus_{\Delta T}(r)<$ 2.5 are depicted in yucca yellow.

\subsection{Nadir view}

From the results of the RETIRA index computed on the investigated area before and after the Wenchuan earthquake using AATSR BT data (nadir view) from April 6, 2008, to April 26, 2008 (Figure 3), the feature of the anomalies could be summarized as follows:

1) From April 6, obvious infrared radiation anomalies appeared along the Yingxiu-Beichuan fault of the northeast epicenter.

2) From April 7, obvious infrared radiation anomalies also appeared on Longquan- Shanxi fault, Lianfeng fault and Xianning-Shuicheng fault of the southeast epicenter, and then conjugate phenomenon of the two direction anomalies appear on April 8, and distributed along the fault zone.

3) The infrared radiation anomalies disappear on Longquan-Shanxi fault, Lianfeng fault and XianningShuicheng fault since April 9, and there is the southward diffusion trend of the infrared radiation anomalies on the Yingxiu Beichuan fault. And then conjugate phe- 

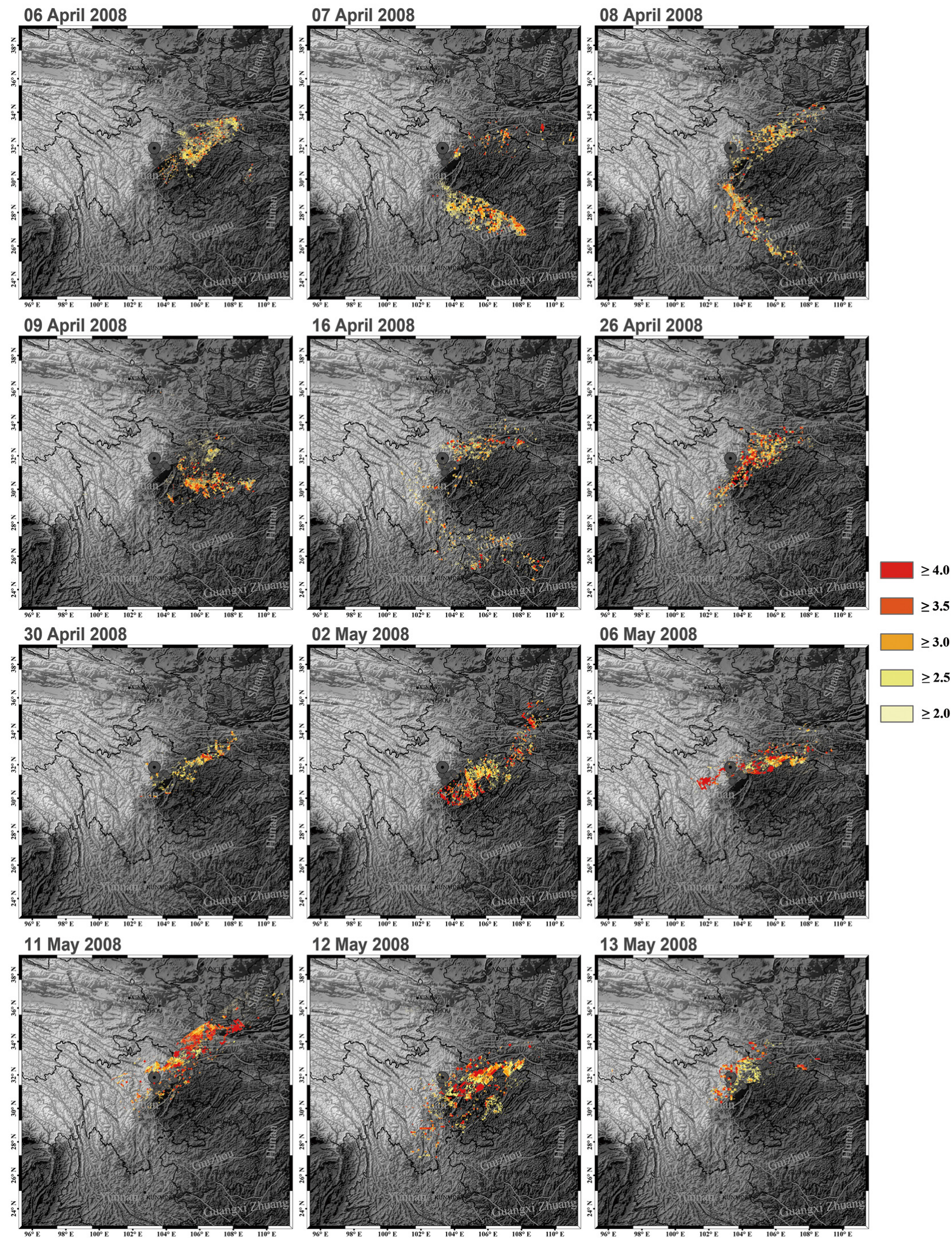

Figure 3. Results of the RETIRA index computed on the investigated area before and after the Wenchuan earthquake using AATSR BT data(Nadir view) from April 6, 2008, to May 13, 2008.

nomenon of two direction anomalies appear on April 16 , and distributed discretely along the fault zone.

4) From April 26, the infrared radiation anomalies disappeared in the direction of Longquan-Shanxi fault,
Lianfeng fault and Xianning-Shuicheng fault, the infrared radiation anomalies on the Yingxiu-Beichuan fault developed continually, and showed increasing trend, until one day before the Wenchuan earthquake, the in- 


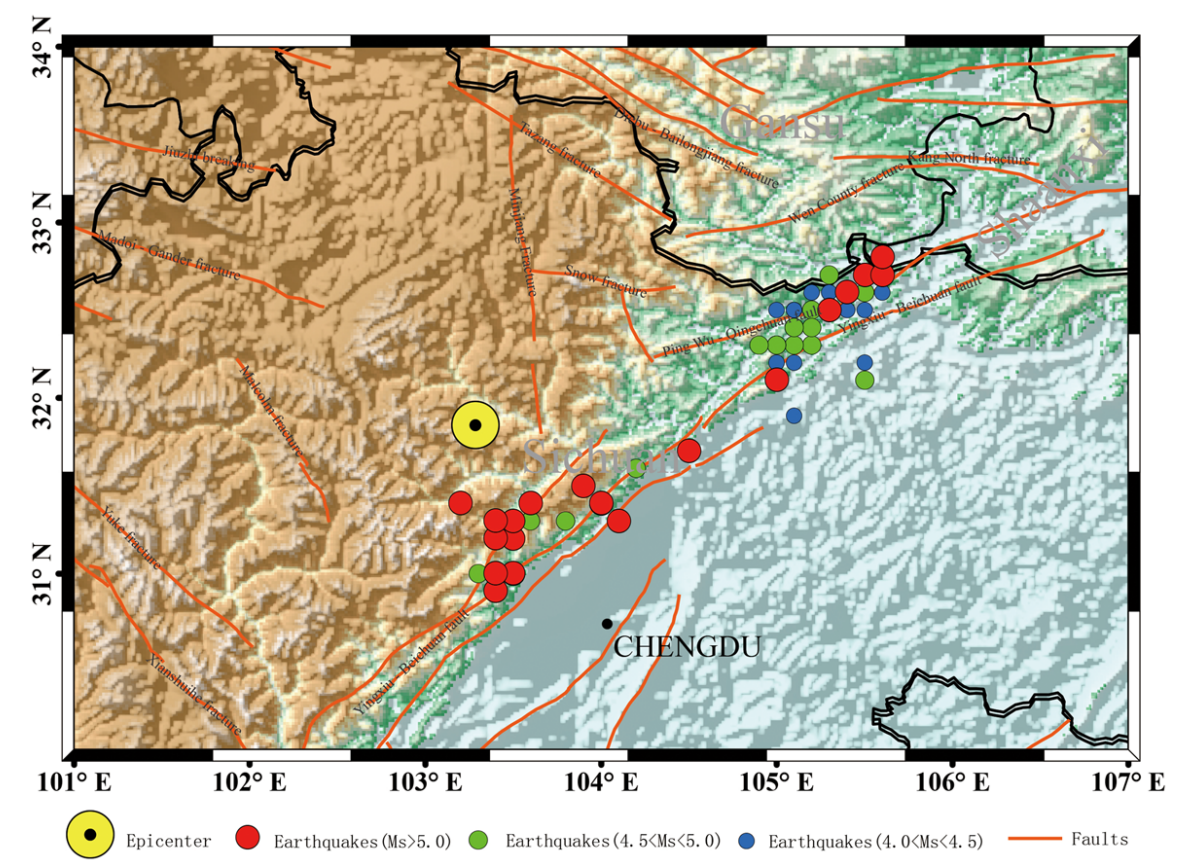

Figure 4. The investigated area of the Yingxiu-Beichuan fault seismic fault.

frared radiation anomalies reach maximum value, the distribution of anomalies spread to the northeast along the structure.

5) Infrared radiation anomalies is dispersoid-like distribution on the day of Wenchuan earthquake (on May 12), and has consistent with the direction of the Yingxiu-Beichuan fault.

6) The infrared radiation anomalies are discrete after that the crustal stress has released, and has distributed around the epicenter on May 13, 2008.

Infrared radiation of the Wenchuan earthquake distributed obviously along the Yingxiu-Beichuan fault. In order to do further analysis on the infrared radiation feature of the Wenchuan earthquake, this paper reduced the study area and selected the Yingxiu-Beichuan fault zone as the research area (Figure 4).

From the results (Figure 5) of the RETIRA index computation on the investigated area before and after the Yingxiu-Beichuan fault using AATSR BT data (Nadir view) from April 6, 2008, to May 13, 2008, we could conclude the following features: the infrared radiation anomalies appear along the south of the fault before Wenchuan earthquake. More obvious infrared radiation anomalies are along the north of fault zone, and the period is long, and the infrared radiation anomalies reaches the maximum value on the day of the earthquake (May 12), after the earthquake (May 13) it shrink microscopically to epicenter area, the intensity of infrared radiation anomalies have weaken.

\subsection{Forward view}

As Figure 6 shows, we could conclude that the feature of infrared anomalies from forward view and nadir view are similar, but not the same. The main feature is that obvious earthquake infrared radiation anomalies appear along the Yingxiu-Beichuan fault, the process of anomalies preparation appears diffuse type, and the area of anomalies is large but the strength of anomalies decreases, the direction of the anomalies is not obvious, and there are not tight relationship between the fault and the anomalies.

The results of the RETIRA index computed on the investigated area between nadir view and forward view data are great different. The possible reasons could be concluded that the local changes in development of seismic activity fault is small, but infrared anisotropy information of seismic activity is very obvious. The Advanced Along-Track Scanning Radiometer onboard ESA's Envisat spacecraft has a viewing geometry where each terrestrial scene is viewed at two angles, at nadir and at a forward angle of $55^{\circ}$. From the dual views, we get the different pattern of ground, especially in complicated terrain area. And these dual views can be used to detect seismic anomalies from bi-directional observation based on infrared anisotropy of seismic activities.

\subsection{Confutation analysis}

In order to examine the reliability of the analysed results for the Wenchuan earthquake above, we use the same procedure to perform a confutation analysis on a relatively seismically unperturbed period: the same period (from April 6, 2009, to May 13, 2009) but in a different year (2009) on the same investigated area (Figure 7).

The anomalies from Figure 7 are not obvious and in discontinuity. Only isolated anomalous pixels are detected. From the quick comparison between images in 

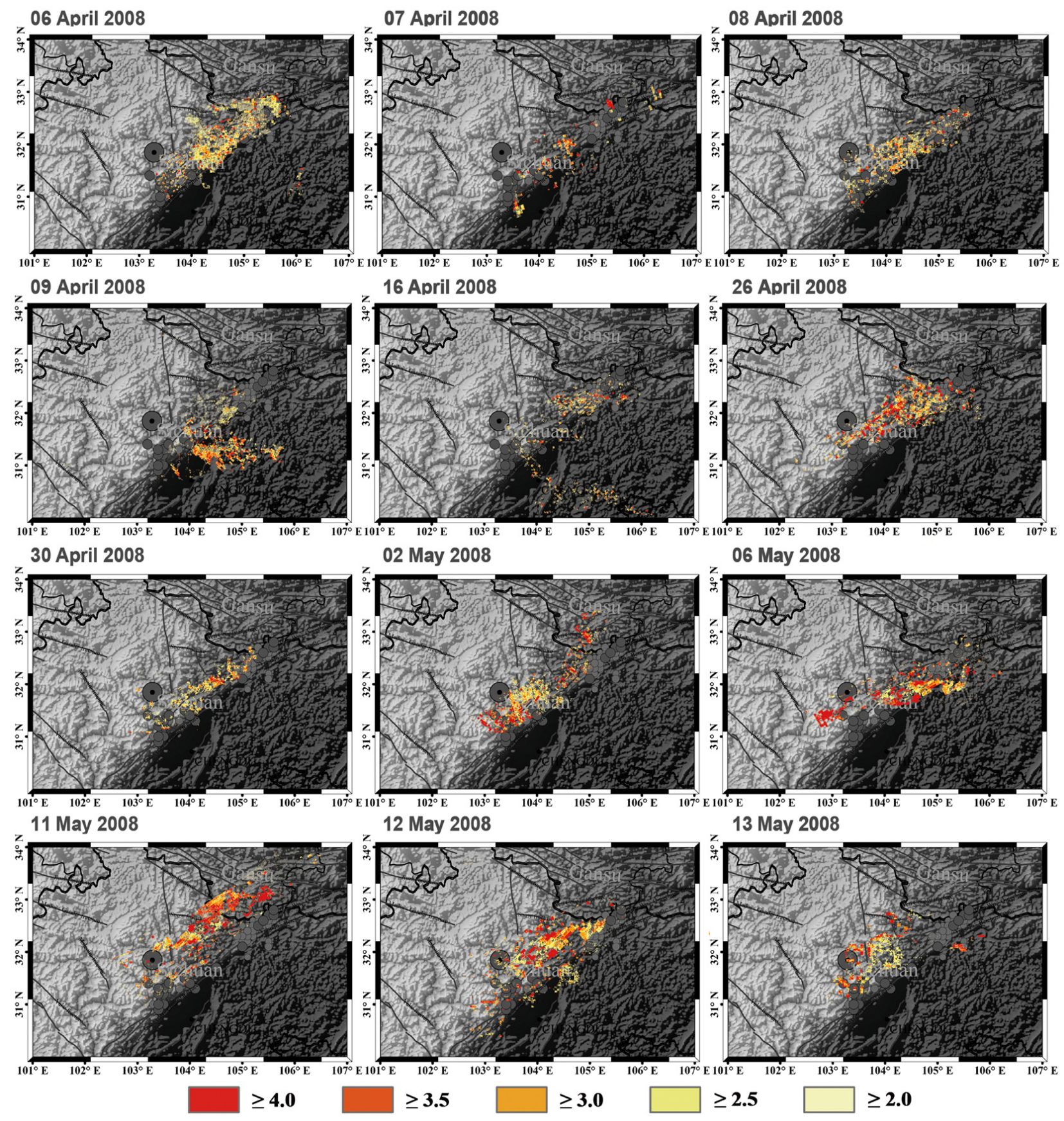

Figure 5. Results of the RETIRA index computation on the investigated area before and after the Yingxiu-Beichuan fault using AATSR BT data (Nadir view) from April 6, 2008, to May 13, 2008.

Figure 3 and confutation phases (Figure 7) allows us to realize that a substantial difference exists in the occurrence of TIR anomalies. In fact, it is evident, from the results shown in Figure 7, that only isolated (April 6, April 8, April 16, May 2 and May 11) and not time persistent anomalous pixels are detected. From Figure 7, it also shows a closer view of these sporadic anomalies.

\section{Conclusion}

This paper has developed the methods of robust satellite data analysis techniques to detect seismic anomalies, and formed a set of data processing procedure. On this basis, this paper has carried out the case study of the Wenchuan earthquake using the EnvisatAATSR bi-angular infrared data, which also has explored the applicability of multi-angle infrared remote sensing in the study of seismic infrared radiation anomalies. The main conclusions of this paper could be drawn as follow:

1) This paper has used the RETIRA index to detect the seismic infrared radiation anomalies, and the detected infrared radiation anomalies can be characterized by the signal-to-noise ratio, the greater earthquake-related noise information, and the smaller the RETIRA index, and vice versa. Therefore, the RETIRA index could avoid the infrared anomalies caused by non-shock, and 

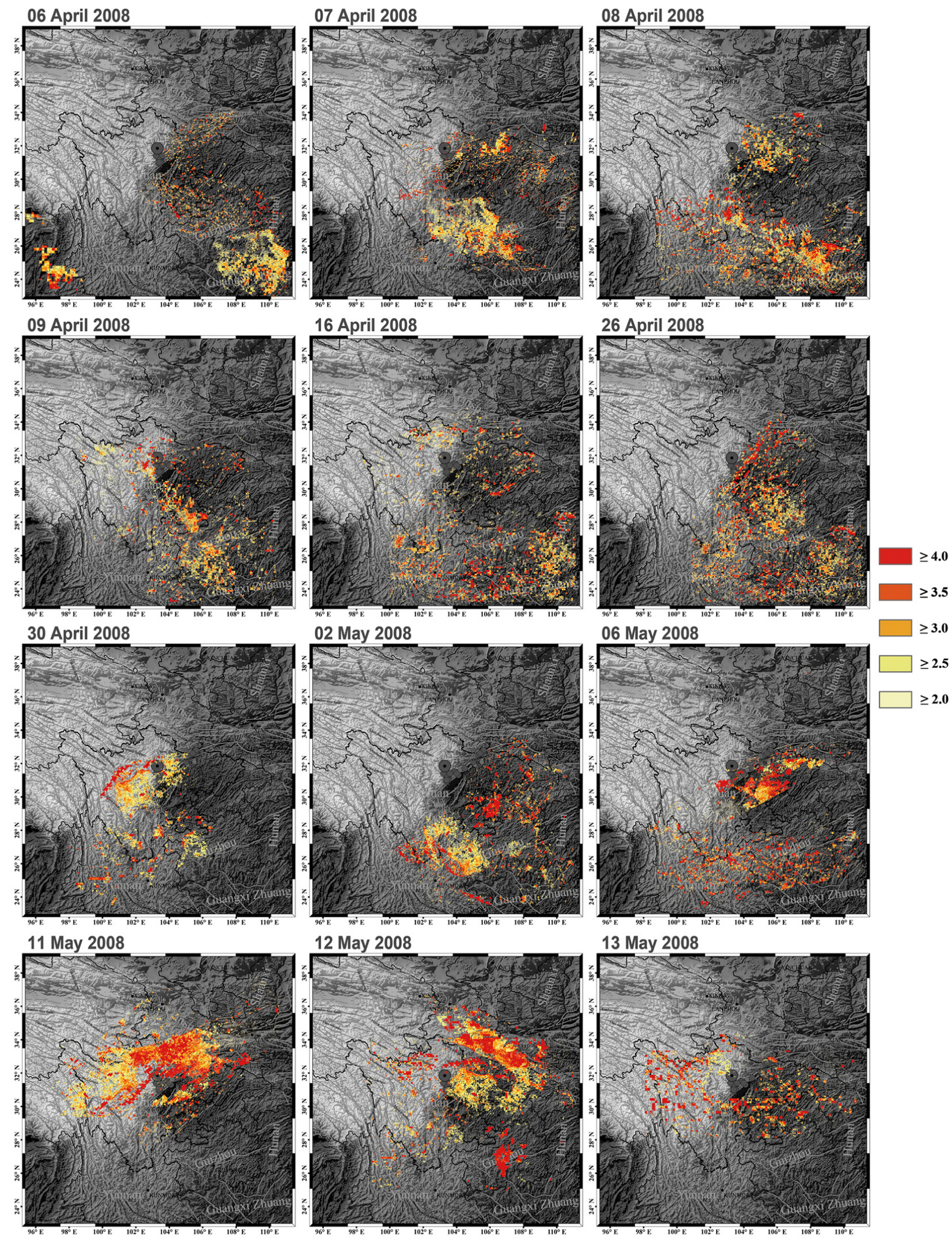

Figure 6. Results of the RETIRA index computation on the investigated area before and after the Wenchuan earthquake using AATSR BT data (Forward view) from April 6, 2008, to May 13, 2008.

has excellent robustness to detect seismic infrared anomalies.

2) The seismic anomalies characteristic detected by the AATSR nadir BT data is better than the forward
BT data, which show up in that there are tighter relationship between structure and the anomalies, the spatial and temporal development of seismic infrared radiation characteristics is more obvious, and is more 

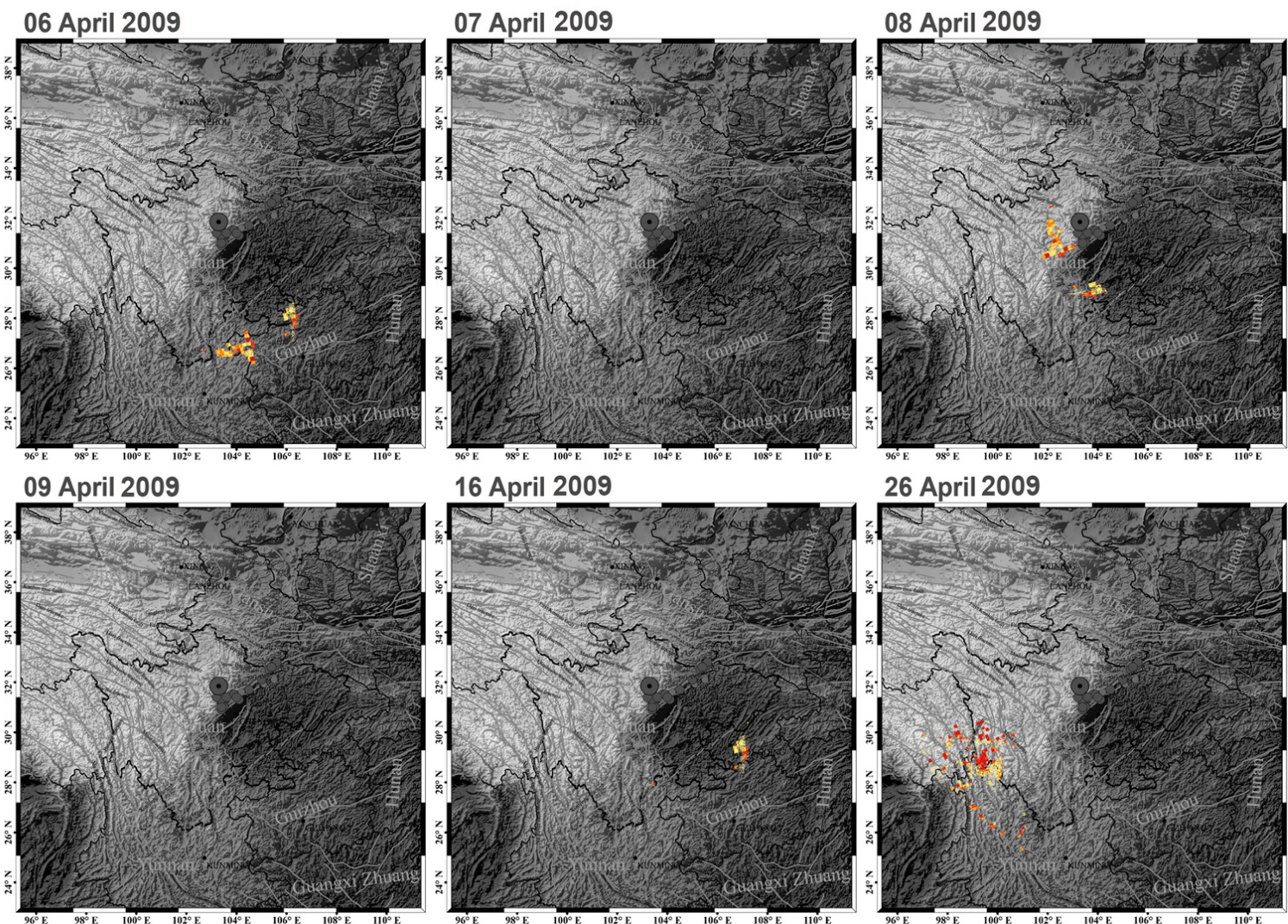

16 April 2009

\section{April 2009}
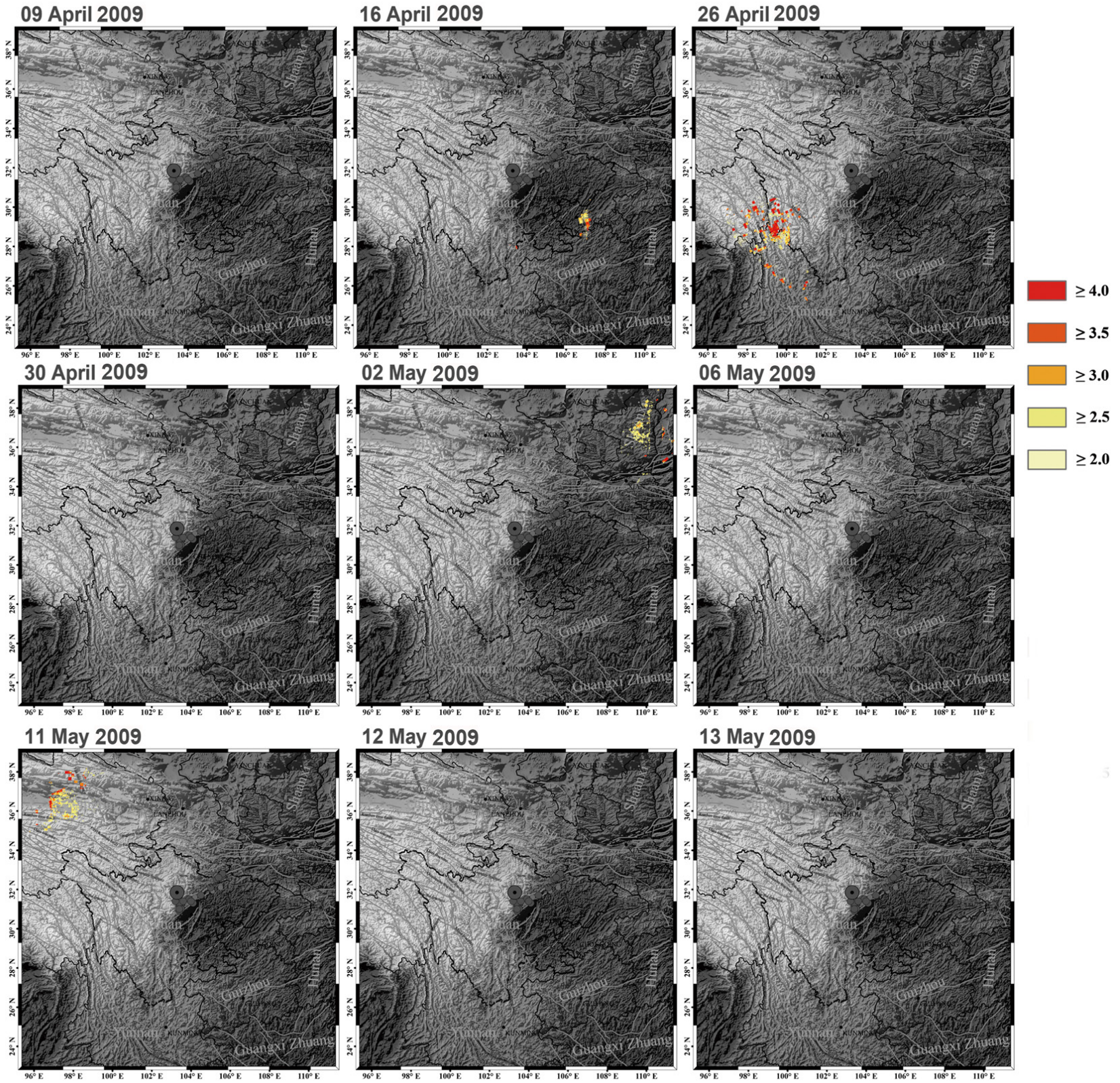

Figure 7. Results of the RETIRA index computation on the investigated area before and after the Wenchuan earthquake using AATSR BT data (Nadir view) from April 6, 2009, to May 13, 2009.

close to the fault activity from the results of the RETIRA index using the nair view data.

3) Combining with the rupture structure data of the Wenchuan earthquake, the analysis shows that, the main structure activity (the Yingxiu-Beichuan fault) characteristics of Wenchuan earthquake can be identified and extracted using the bi-angular AATSR nadir and forward brightness temperature data, and the seis- 
mic infrared radiation anomalies detected by the AATSR nadir brightness temperature is more close to Yingxiu-Beichuan fault activity.

Therefore our studies provide a finding that anomalies discovered within Envisat-AATSR bi-angular infrared data could be regarded as an effective indicator to detect seismic anomalies. This finding will be further validated by using more earthquake data in the future.

Acknowledgements. This work is founded by Basic Science Research Project of Institute of Earthquake Science, China Earthquake Administration (Grant No. 2015IES0306 and 2013IES0101), Civil Specific Advance Research Program on Science, Technology and Industry for National Defense (Grant No. 60128303) and International Science and Technology Cooperation Program of China (Grant No. 2012DFR20440). The authors would like to acknowledge European Space Agency (ESA) for making AATSR data available for various research communities, and thank referees for their useful comments.

\section{References}

Aliano, C., R. Corrado, C. Filizzola, N. Pergola and V. Tramutoli (2007). Robust Satellite Techniques (RST) for Seismically Active Areas Monitoring: the Case of 21st May, 2003 Boumerdes/Thenia (Algeria) Earthquake, In: MultiTemp 2007. International Workshop on the Analysis of Multi-temporal Remote Sensing Images (Leuven, Belgium, July 18-20, 2007), 6 pp.

Campbell, J.W., J.M. Blaisdell and M. Darzi (1995). Level-3 SeaWIFS data products: spatial and temporal binning algorithms, NASA technical memorandum 104566, vol. 32, 80 pp.

Cervone, G., M. Kafatos, D. Napoletani and R.P. Singh (2004). Wavelet maxima curves of surface latent heat flux associated with two recent Greek earthquakes, Nat. Hazards Earth Syst. Sci., 4, 359-374.

Cervone, G., R.P. Singh, M. Kafatos and C. Yu (2005). Wavelet maxima curves of surface latent heat flux anomalies associated with Indian earthquakes, Nat. Hazards Earth Syst. Sci., 5, 87-99.

Coll, C., E. Valor, J.M. Galve, M. Mira, M. Bisquert, V. García-Santos, E. Caselles and V. Caselles (2012). Long-term accuracy assessment of land surface temperatures derived from the Advanced Along-Track Scanning Radiometer, Remote Sens. Environ., 116, 211-225.

Corrado, R., R. Caputo, C. Filizzola, N. Pergola, C. Pietrapertosa and V. Tramutoli (2005). Seismically active area monitoring by robust TIR satellite techniques: a sensitivity analysis on low magnitude earthquakes in Greece and Turkey, Nat. Hazards Earth Syst. Sci., 5, 101-108.

Defu, L., L. Zhuoli and P. Keyin (1997). OLR anomalous phenomena before strong earthquakes, Earthquake, 17, 126-132.

ESA (2007). Envisat AATSR Product Handbook, Euro- pean Space Agency.

Filizzola, C., N. Pergola, C. Pietrapertosa and V. Tramutoli (2004). Robust satellite techniques for seismically active areas monitoring: a sensitivity analysis on September 7, 1999 Athens's earthquake, Phys. Chem. Earth, Parts A/B/C, 29, 517-527.

Llewellyn-Jones, D., M. Edwards, C. Mutlow, A. Birks, I. Barton and H. Tait (2001). AATSR: global-change and surface-temperature measurements from Envisat, ESA bulletin, 105, 11-21.

Ouzounov, D., and F. Freund (2004). Mid-infrared emission prior to strong earthquakes analyzed by remote sensing data, Adv. Space Res., 33, 268-73.

Ouzounov, D., D. Liu, K. Chunli, G. Cervone, M. Kafatos and P. Taylor (2007). Outgoing long wave radiation variability from IR satellite data prior to major earthquakes, Tectonophysics, 431, 211-220.

Temimi, M., T. Lacava, T. Lakhankar et al. (2011). A multi-temporal analysis of AMSR-E data for flood and discharge monitoring during the 2008 flood in Iowa, Hydrol. Process., 25, 2623-2634.

Tramutoli, V. (1998). Robust AVHRR Techniques (RAT) for Environmental Monitoring theory and applications, In: Proceedings of the SPIE, vol. 3496: Earth surface remote sensing II, 101-113.

Tramutoli, V., G. Di Bello, N. Pergola and S. Piscitelli (2001). Robust satellite techniques for remote sensing of seismically active areas, Annals of Geophysics, 44, 295-312.

Tramutoli, V. (2005). Robust Satellite Techniques (RST) for natural and environmental hazards monitoring and mitigation: ten years of successful applications, ISP MSRS 2005 Conference Proceedings, Beijing, China.

Tramutoli, V., V. Cuomo, C. Filizzola, N. Pergola and C. Pietrapertosa (2005). Assessing the potential of thermal infrared satellite surveys for monitoring seismically active areas: The case of Kocaeli (İzmit) earthquake, August 17, 1999, Remot. Sens. Environ., 96, 409-426.

Tramutoli, V. (2007). Robust Satellite Techniques (RST) for Natural and Environmental Hazards Monitoring and Mitigation: Theory and Applications, In: MultiTemp 2007. International Workshop on the Analysis of Multi-temporal Remote Sensing Images (Leuven, Belgium, July 18-20, 2007), 6 pp.

Tramutoli, V., C. Aliano, R. Corrado et al. (2013). On the possible origin of thermal infrared radiation (TIR) anomalies in earthquake-prone areas observed using robust satellite techniques (RST), Chem. Geol., 339, 157-168.

Tronin, A.A., M. Hayakawa and O.A. Molchanov (2002). Thermal IR satellite data application for earthquake 
research in Japan and China, J. Geodyn., 33, 519-534. Tronin, A.A., P.F. Biagi, O.A. Molchanov, Y.M. Khatkevich and E.I. Gordeev (2004). Temperature variations related to earthquakes from simultaneous observation at the ground stations and by satellites in Kamchatka area, Phys. Chem. Earth, 29, 501-506.

Xiong, P., Y. Bi and X. Shen (2009a). A Wavelet-Based Method for Detecting Seismic Anomalies in Remote Sensing Satellite Data, In: P. Perner (ed.), Machine Learning and Data Mining in Pattern Recognition, Springer, Berlin-Heidelberg, 569-581.

Xiong, P., Y. Bi and X. Shen (2009b). Study of Outgoing Longwave Radiation Anomalies Associated with Two Earthquakes in China Using Wavelet Maxima, In: Hybrid Artificial Intelligence Systems (4th International Conference, HAIS 2009, Salamanca, Spain, June 10-12, 2009), 77-87.

Xiong, P., X.H. Shen, Y.X. Bi et al. (2010). Study of outgoing longwave radiation anomalies associated with Haiti earthquake, Nat. Hazards Earth Syst. Sci., 10, 2169-2178.

Xiong, P., X. Gu, X. Shen, X. Zhang, C. Kang and Y. Bi (2011). Wavelet-Based Method for Detecting Seismic Anomalies in DEMETER Satellite Data, In: Knowledge Science, Engineering and Management (5th International Conference, KSEM 2011, Irvine, CA, USA, December 12-14, 2011), 1-11.

Xiong, P., X.F. Gu, Y.X. Bi et al. (2013). Detecting seismic IR anomalies in bi-angular Advanced AlongTrack Scanning Radiometer data, Nat. Hazards Earth Syst. Sci., 13, 2065-2074.

Závody, A.M., C.T. Mutlow and D.T. Llewellyn-Jones (2000). Cloud clearing over the ocean in the processing of data from the Along-Track Scanning Radiometer (ATSR), J. Atmos. Ocean. Tech., 17, 595-615. 